\title{
ATTENUATION OF WAVES FROM BOAT WAKES IN MIXED MANGROVE FOREST OF RHIZOPHORA AND BRUGUIERA SPECIES IN MATANG, PERAK
}

Isfarita Ismail1, Mohd Lokman Husain2, Rozaimi Zakaria3

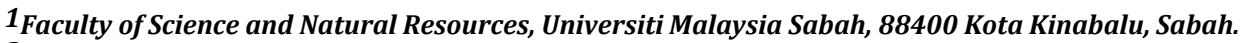

2 Institute of Oceanography and Environment (INOS), Universiti Malaysia Terengganu, 21030 Kuala Terengganu, Terengganu.

3 Mathemtaics, Graphics and Visualization Research Group (M-GRAVS), Faculty of Science and Natural Resources, Universiti Malaysia Sabah, 88400 Kota Kinabalu, Sabah.

Corresponding author E-mail: isfarita@yahoo.com ${ }^{1}$, mlokmn@umt.edu.my ${ }^{2}$, rozaimi@ums.com.my ${ }^{3}$

This is an open access article distributed under the Creative Commons Attribution License, which permits unrestricted use, distribution, and reproduction in any medium, provided the original work is properly cited.

\section{ARTICLE DETAILS}

\section{ARTICLE HISTORY:}

\section{Received 12 May2017}

Accepted 12 July 2017

Available online 10 September 2017

\section{KEYWORDS:}

Wave attenuation, boat wake wave height, wave reduction, mixed mangrove (of Rhizophora and Bruguiera species), Matang mangrove forest, Perak

\section{ABSTRACT}

In Malaysia, there are several small rivers and estuaries which are frequented by fishing boats. The wave action due to the movement of boats impact the coastal morphology of the area. In this paper, we have studied the wave reduction in mixed mangrove forest of Rhizosphere and Bruguiera species based on field observations of waves from boat wakes in Sg. Sangga Kecil of Matang forest reserve, west coast of Peninsular Malaysia. The unique physical characteristics of Bruguiera sp. and Rhizophora sp. such as the intricate knee root and numerous pneumatophores, respectively, impact the wave amplitudes in the mangrove forest. The reduction of wave amplitudes in a $15 \mathrm{~m}$ long transect of mixed mangrove forest at a given study site has been analysed in the present study. It is found that the wave reduction for each $5-\mathrm{m}$ distance from the vegetation edge ranged from $47.4 \%$ to $9.6 \%$. However, on a cumulative basis the wave reduction inside the mixed mangrove forest ranged between $47.4 \%$ to $72.8 \%$, with an average of $63 \%$. As far as the vertical trend is concerned the wave reduction in $(0-10 \mathrm{~cm})$ level was $88.7 \%$ while in $(10-20 \mathrm{~cm})$ level it was found to be $61.2 \%$.

\section{INTRODUCTION}

Mangroves are coastal forests that are found in sheltered estuaries and along river banks and lagoons in the tropics and subtropics. Mangroves worldwide cover an approximate area of $240000 \mathrm{~km} 2$ of sheltered coastlines in the tropics and subtropics [1]. They are distributed within the tropics and subtropics, reaching their maximum development between $250 \mathrm{~N}$ and $250 \mathrm{~S}$. The first attempt to estimate total mangrove area worldwide was undertaken as part of the Food and Agriculture Organization of the United Nations (FAO) and United Nations Environment Programme (UNEP) Tropical Forest Resource Assessment in 1980 [2].

Mangrove forest ecosystems fulfil many important functions and provide a wide range of services at the local and national levels. Mangroves support the conservation of biological diversity by providing habitats, spawning grounds, nurseries and nutrients for many animals. Mangrove ecosystem is also used for aquaculture, both as open- water estuarine maricultural and as pond culture. The physical importance of mangrove is to act as a wave buffer. The December 2004 tsunami highlighted the physical importance of mangroves.

The study about the physical processes in mangrove forest is still poorly understood due to the lack of extensive research on the subject. As stated in a research, it is only a short time since the studies of the physical processes in mangrove areas have been initiated $[3,4]$. Some researcher has studied some tidal periodic phenomena in mangrove areas along rivers or estuaries protected from the open sea [5-9].

In the present study, we have analysed the reduction in the amplitude of waves produced by the passage of fishing boats in an estuary as these waves travel through the Matang mangrove forest area of
Perak. The paper focuses on the mixed mangrove forest of Rhizophora and Bruguiera species which was chosen because they are dominant species in the area. At a selected site, we have chosen a transect which has the longest distance of $15 \mathrm{~m}$ inside the mangrove forest. The combination of two mangrove species along the transect had the desired effect of the wave attenuation. The main objective of this paper is to quantify the percentage of wave reduction by the mixed mangrove vegetation of Rhizophora sp. and Bruguiera sp. in Matang reserve area, Perak.

A relation between wave reduction and horizontal distance as well as the vertical height (water level) has been analysed in detail. It is found that the wave reduction along the transect, in each $5-\mathrm{m}$ distance from the vegetation edge, decreased from $47.4 \%$ to $9.6 \%$. However, on a cumulative basis the wave reduction increased with increasing distance inside the mangrove forest, ranging from $47.4 \%$ to $72.8 \%$, with an average increase of $63 \%$. As far as the vertical trend is concerned the wave reduction in $(0-10 \mathrm{~cm})$ level was $88.7 \%$ while in $(10-20 \mathrm{~cm})$ level it was found to be $61.2 \%$, showing that the wave reduction decreases with increasing water level.

\section{METHODOLOGY}

\subsection{Study area}

The Matang forest reserve is a unique ecosystem and covers an area of 40 711 ha, along a $52 \mathrm{~km}$ stretch of the northern coast of Perak in tropical Malaysia which has been systematically managed by the Forestry Department since 1904 [10]. Matang mangroves are transacted by numerous rivers, large and small. As a result, $70 \%$ of its landscape comprises of islands. We have chosen the study site on the bank of Sungai Sangga Kecil which is located within the Matang mangrove forest area, Perak. This region is a forest reserve and based on a survey conducted in 2000 , its area has grown by over $3 \%$, which is equivalent to 1,250 hectares. Most areas in Matang mangrove forest are covered by pure stand of bakau forest (Rhizophora). There are also large areas of 
Avicennia and Nypa, with patches of Berus, Lenggadai, and Tumu forest. However, Rhizophora makes up about $85 \%$ of the total forest area.

Over 85 per cent of Matang mangroves are tidally influenced, undergoing a regiment of being flooded by saltwater followed by a drying out period. Climate is monsoonal with an average annual rainfall of $3500-4800 \mathrm{~mm}$ [11]. Rainfall normally peaks in May and November, coinciding with the southwest and northeast monsoons.

Figure 1 shows the study site on the bank of Sg. Sangga Kecil. At this location, we have chosen a $15 \mathrm{~m}$ long transect from the vegetation's edge, which is dominated by a mixed mangrove of Rhizophora and Bruguiera sp. Rhizophora sp. have numerous pneumatophores while Bruguiera sp. have intricate knee root system.

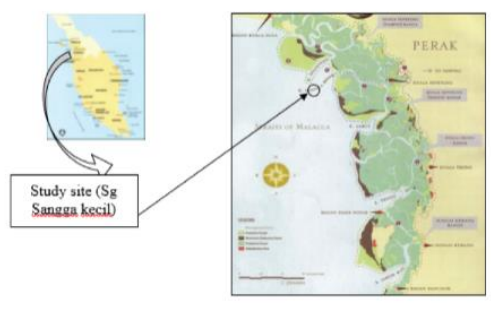

Figure 1: Map of Matang mangrove forest area, Perak.

Figure 2 shows the mixed mangrove forest for Rhizophora sp. and Bruguiera sp. meanwhile Figure 3 shows a $15-\mathrm{m}$ idealized transect of Rhizophora sp. and Bruguiera sp. inside the mangrove forest.
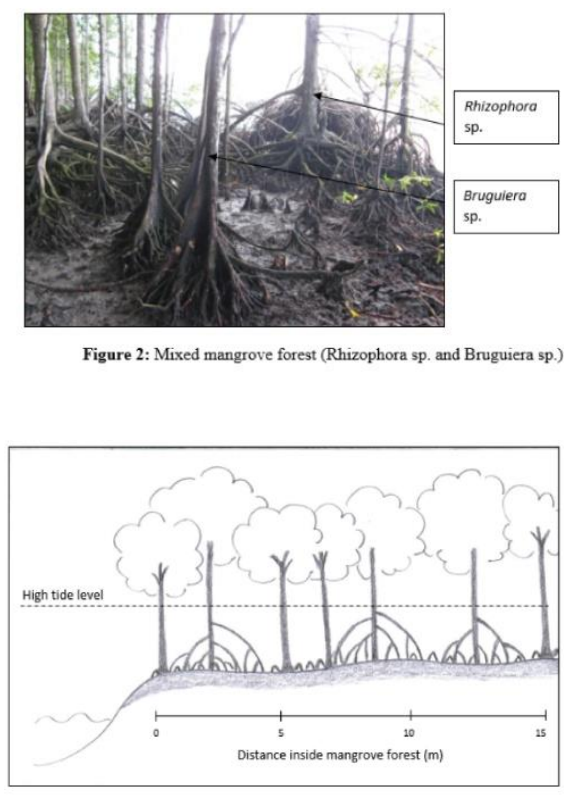

Figure 3: Idealized transect of Rhizophora sp. and Bruguiera sp

\subsection{Observation of wave data}

Upstream of the estuary near the study site there is a fishing village located at Bagan Sangga Kecil. This ensures a steady stream of fishing boats which move in and out of the area, creating waves in their wakes. The wave height data were collected using water loggers (Boart Longyear Interfels, Germany). The parameters that can be obtained from the water loggers are water depth, pressure and temperature. However, we have used only the water depth in our study. The time interval for the water logger recording is 1 second.

The wave fluctuations recorded by the water logger due to each passing boat is called a wave burst, which ride over the tidal wave and are captured by the water logger [12]. It may be noted that during the observation the number of wave bursts were about 20 out of which only 5 were chosen for purpose of analysis of the wave data.

Along the transect we chose 4 locations, each $5 \mathrm{~m}$ apart. The first location at the vegetation's edge has been designated as plot 0 , while plot 1 refers to the next location $5 \mathrm{~m}$ inside the mangrove, and so on. In this study, the water loggers were set up simultaneously at plots $0,1,2$ and 3 for one tidal cycle during the spring tide. Table 1 shows the sampling variability giving the date, reading and the number of wave bursts. For reading 1 the water loggers were set up at plot 0 and plot 1 . For reading 2 they were fixed at plot 0 and plot 2 , and so on.

Table 1: Sampling variability using four water loggers for mixed mangrove (Rhizophora sp. and Bruguiera sp.)

\begin{tabular}{|c|c|c|c|c|c|c|}
\hline \multirow[b]{2}{*}{ Date } & \multirow[b]{2}{*}{ Reading } & \multirow[b]{2}{*}{$\begin{array}{l}\text { Number of } \\
\text { wave burst }\end{array}$} & \multicolumn{4}{|c|}{ Distance (m) } \\
\hline & & & 0 & 5 & 10 & $\begin{array}{l}1 \\
5\end{array}$ \\
\hline $17 / 6 / 2008$ & 1 & 5 & $\sqrt{ }$ & $\sqrt{ }$ & & \\
\hline $17 / 6 / 2008$ & 2 & 5 & $\sqrt{ }$ & & $\sqrt{ }$ & \\
\hline $17 / 6 / 2008$ & 3 & 5 & $\sqrt{ }$ & & & $\sqrt{ }$ \\
\hline
\end{tabular}

Figure 4 shows the example of a wave burst and identification of associated waves for mixed mangrove in Matang forest area. Each burst contains a set of waves. Wave heights of less than $2 \mathrm{~cm}$ are taken as water movement due to the wind, and hence not considered as boat induced waves. Thus, only water levels of more than $2 \mathrm{~cm}$ are considered in the computation of wave height.

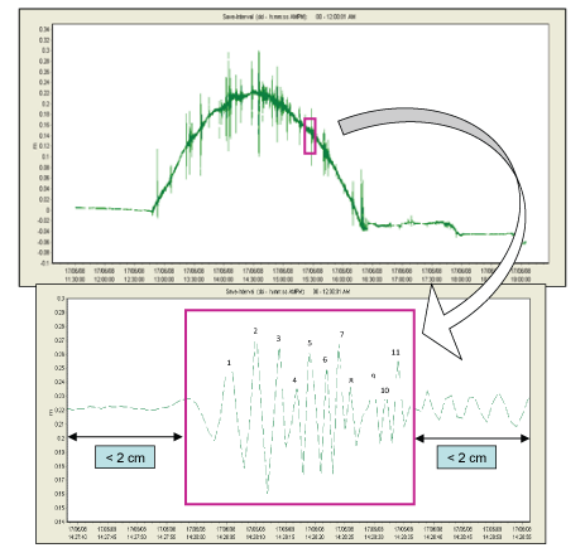

Figure 4: Example of a wave burst and identification of associated waves. After identifying the waves 1 to 11 in Figure 4, their mean wave height was used to compute the wave reduction [13]. Following , the wave reduction is given by,

where, reduction, percentage reduction $=\mathrm{rx} 100$

$=$ wave height in front of mangrove (plot 0 )

= wave height at a location' $L^{\prime}$ inside the mangrove forest

\section{RESULTS AND DISCUSSION}

Figure 5 shows the wave data collected simultaneously by the four water loggers fixed at plot $0,1,2$ and 3 , respectively. For this experiment, three sets of data analyses were conducted corresponding to readings 1,2 and 3 .

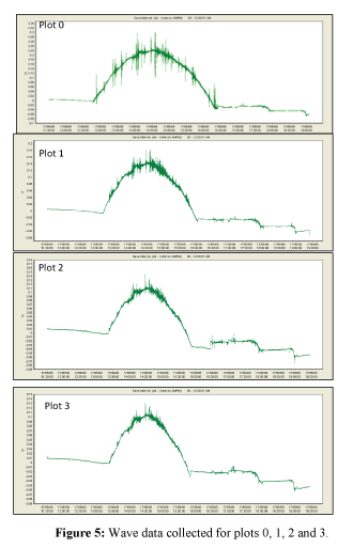

Table 2 gives the average percentage of cumulative wave reduction as the waves travel $15 \mathrm{~m}$ inside the mixed mangrove forest of Rhizophora and Bruguiera species. For reading 1 , the wave reduction is $47.4 \%$ which is 
the average reduction in wave heights of the five wave bursts over a $5-\mathrm{m}$ distance. Similarly, over a $10-\mathrm{m}$ distance the average reduction is $68.8 \%$, and so on. Thus, it is seen from the table that the wave reduction increases with increasing distance inside the mangrove forest with an overall average reduction of $63 \%$.

The roots/stems of the mangrove trees attenuate the waves more and more as the waves travel inside the mixed mangrove forest. The increase in wave reduction shows the mixed mangrove can attenuate the incoming wave effectively. This result is similar to the observational study of who found that the root system of the mangrove is one of the primary components that help in the reduction of waves [14]. For the relation between the average wave reduction and the distance inside the mangrove forest is it may be seen that average wave reduction increases with increasing distance inside the mangrove.

Table 2: Cumulative wave reduction inside the mangrove forest

\begin{tabular}{|c|c|}
\hline Reading & Average Wave Reduction (\%) \\
\hline $1(0-5 \mathrm{~m})$ & 47.4 \\
\hline $2(0-10 \mathrm{~m})$ & 68.8 \\
\hline $3(0-15 \mathrm{~m})$ & 72.8 \\
\hline Overall Average & 63.0 \\
\hline
\end{tabular}

On a more detailed analysis, the data was also used for wave reduction over each plot of $5 \mathrm{~m}$ distance along the transect as presented in Table 3 . It is seen from the table that in the first $5 \mathrm{~m}$ the wave was reduced by $47.4 \%$ while for the next $5 \mathrm{~m}(5-10 \mathrm{~m})$ it reduced further to $43.1 \%$.

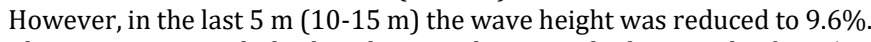
Thus, we may conclude that the root density is highest in the first $5 \mathrm{~m}$ resulting in $47.4 \%$ reduction in wave height. This is followed by a reduction of $43.1 \%$ in the next $5 \mathrm{~m}$ and suggesting that the root density was less but closer to the root density in the first $5 \mathrm{~m}$. In the last $5 \mathrm{~m}$, the wave reduction was only $9.6 \%$ as the root density was substantially lower in comparison to the first or the second $5 \mathrm{~m}$ distance inside the mangrove forest. From this study, it may be inferred that the first $10 \mathrm{~m}$ within the mangrove forest are most effective in the attenuation of the wave height.

Table 3: Wave reduction for each 5-m distance inside the mangrove forest

\begin{tabular}{|c|c|}
\hline Distance (m) & $\begin{array}{c}\text { Average Wave Reduction } \\
(\%)\end{array}$ \\
\hline 0 and 5 & 47.4 \\
\hline 5 and 10 & 43.1 \\
\hline 10 and 15 & 9.6 \\
\hline
\end{tabular}

We have also analysed the vertical trend of wave reduction in the mixed mangrove forest. At the study site, the wave reduction was found in $0-20$ $\mathrm{cm}$ level as the tidal amplitude at the time of the experiment was about 20 $\mathrm{cm}$. This means that in this case the wave reduction did not exist above 20 $\mathrm{cm}$. The percentage of wave reduction is highest in $0-10 \mathrm{~cm}$ level $(88.7 \%)$ because in this level there are many big roots which tend to attenuate the waves more effectively. Table 4 shows the average wave reduction vs. vertical height (each $10-\mathrm{cm}$ level) for the mixed mangrove forest. It is found that the wave reduction decreases with increasing water level [12, $14]$.

Table 4: Wave reduction for vertical layer (each $10 \mathrm{~cm}$ )
\begin{tabular}{|c|c|}
\hline Level $(\mathrm{cm})$ & Average Wave Reduction $(\%)$ \\
\hline $0-10$ & 88.7 \\
\hline
\end{tabular}

$10-20$

\section{DISCUSSION AND CONCLUSION}

This paper focuses on the investigation of wave reduction in mixed mangrove species (Rhizophora sp. and Bruguiera sp.) at Matang mangrove forest, Perak. These vegetations have their unique characteristics which help in the reduction of the wave height We have chosen a $15 \mathrm{~m}$ transect inside the mangrove forest from the vegetation's edge. For this study, four water loggers were simultaneously used to measure the wave height. The water loggers were put at plots $0,1,2$ and 3 for the three readings. From further analysis, it is seen that the wave reduction increases with increasing distance inside the mangrove forest. Also, it is found that the wave reduction decreases with increasing water level When the waves enter the mangrove forest, the wave height was reduced by $47.4 \%$ in the first $5 \mathrm{~m}$ distance from the vegetation edge; in the next $5 \mathrm{~m}(5-10 \mathrm{~m})$ it has reduced to $43.1 \%$ while in the last $5 \mathrm{~m}(10-15 \mathrm{~m})$ the wave was reduced to $9.6 \%$. In the last $5 \mathrm{~m}$ the wave reduction was small as the root density was substantially lower in comparison to the first or the second $5 \mathrm{~m}$ distance inside the mangrove forest. It may be concluded that the first $10 \mathrm{~m}$ of mixed mangrove are important for wave reduction.

Based on the measurements of wave height the mixed mangrove (Rhizophora sp. and Bruguiera sp.) is found to be good species for wave attenuation. These mixed species can attenuate the waves with about $63 \%$ overall reduction in the wave height over a $15 \mathrm{~m}$ long transect.

\section{ACKNOWLEDGEMENTS}

This study was supported by an e-Science funding from MOSTI (Vot. Number 52012). The authors would like to thank for the facilities provided by the Institute of Oceanography and Environment, Universiti Malaysia Terengganu.

\section{REFERENCES}

[1] Lugo, A.E., and Brown, S. 1990. Tropical secondary forests. Journal of Tropical Ecology, 6 (1), 1-32.

[2] FAO. 2007. The world's mangroves 1980 - 2005. A thematic study prepared in the framework of the Global Forest Resources Assessment 2005. FAO Forestry Paper 153. Rome.

[3] Kjerfve, B. 1990. Manual for investigation of hydrological processes in mangrove ecosystems. 79. New Delhi, India: UNESCO/UNDP.

[4] Mazda, Y. 1993. Present situation of physical study in mangrove regions. Journal of The Faculty of Marine Science and Technology. Tokai University 35, 169-184.

[5] Ridd, P.V., Wolanski, E., and Mazda, Y. 1990. Longitudinal diffusion in mangrove - fringed tidal creeks. Estuarine, Coastal and Shelf Science, 31 (5),

541-554.

[6] Wolanski, E., Mazda, Y., King, B., and Gay, S. 1990. Dynamics, flashing, and trapping in Hinchinbrook Channel, a giant mangrove swamp, Australia. Estuarine, Coastal and Shelf Science 31 (5), 555-579.

[7] Wolanski, E., Mazda, Y., and Ridd, P.V. 1992. Mangrove hydrodynamics. Pp. 43-62 in Robertson AI \& Alongi DM (Eds.) Tropical Mangrove Ecosystems. Coastal and Estuarine Studies. American Geophysical Union, Washington, DC.

[8] Mazda, Y., Yokochi, H., and Sato, Y. 1990. Groundwater flow in the Bashita - Minato mangrove area, and its influence on water and bottom mud properties. Estuarine, Coastal and Shelf Science, 31 (5), 621-638.

[9] Mazda, Y., Kanazawa, N., and Wolanski, E. 1995. Tidal asymmetry in mangrove creeks. Hydrobiologia, 295 (1-3), 51-58.

[10] Ahmad, S. 2009. Recreational values of mangrove forest in Larut Matang, Perak. Journal of Tropical Forest Science, 21 (2), 81-87.

[11] Nieuwolt, S. 1981. The climates of continental Southeast Asia. Pp. 166 in Takahashi K \& Arakawa H (Eds.) Climates of Southern and Western Asia, world survey of climatology. Elsevier Scientific Publishing Company, Amsterdam. 
[12] Quartel, S., Kroon, A., Augustinus, P.G.E.F., Van Santen, P., and Tri, N.H. 2007. Wave attenuation in coastal mangroves in the Red River Delta, Vietnam. Journal of Asian Earth Sciences, 29 (4), 576-584.

[13] Mazda, Y., Magi, M., Kogo, M., and Hong, P.N. 1997. Mangroves as a coastal protection from waves in the Tong King Delta, Vietnam.
Mangroves and Salt Marshes, 1 (2), 127-135.

[14] Mazda, Y., Magi, M., Ikeda, Y., Kurokawa, T., and Asano, T. 2006. Wave attenuation in a mangrove forest dominated by Sonneratia sp. Wetlands Ecology and Management, 14 (4), 365-378.

\section{$x=0 x-20 x=0$}

